Article

\title{
Investigating the Solubility and Activity of a Novel Class of Ice Recrystallization Inhibitors
}

\author{
Anna A. Ampaw (D), Kayla Newell and Robert N. Ben * \\ Department of Chemistry and Biomolecular Sciences, University of Ottawa, D'Iorio Hall, 10 Marie Curie St., \\ Ottawa, ON K1N 6N5, Canada; aampa044@uottawa.ca (A.A.A.); knewe015@uottawa.ca (K.N.) \\ * Correspondence: rben@uottawa.ca; Tel.: +1-613-562-5800
}

Citation: Ampaw, A.A.; Newell, K.; Ben, R.N. Investigating the Solubility and Activity of a Novel Class of Ice Recrystallization Inhibitors. Processes 2021, 9, 1781. https://doi.org/ $10.3390 /$ pr9101781

Academic Editors:

Yoshimichi Hagiwara,

Tomonori Waku and Satoshi Ogata

Received: 16 September 2021

Accepted: 30 September 2021

Published: 6 October 2021

Publisher's Note: MDPI stays neutral with regard to jurisdictional claims in published maps and institutional affiliations.

Copyright: (c) 2021 by the authors. Licensee MDPI, Basel, Switzerland. This article is an open access article distributed under the terms and conditions of the Creative Commons Attribution (CC BY) license (https:// creativecommons.org/licenses/by/ $4.0 /)$.

\begin{abstract}
O$-aryl- $\beta$-D-glucosides and $N$-alkyl-D-gluconamides are two classes of effective ice recrystallization inhibitors (IRIs), however their solubilities limit their use in cryopreservation applications. Herein, we have synthesized and assessed phosphonate analogues of small-molecule IRIs as a method to improve their chemical and physical properties. Four sodium phosphonate compounds 4-7 were synthesized and exhibited high solubilities greater than $200 \mathrm{mM}$. Their IRI activity was evaluated using the splat cooling assay and only the sodium phosphonate derivatives of $\alpha$-methyl-D-glucoside (5-Na) and $N$-octyl-D-gluconamide (7-Na) exhibited an $\mathrm{IC}_{50}$ value less than $30 \mathrm{mM}$. It was found that the addition of a polar sodium phosphonate group to the alkyl gluconamide (1) and aryl glucoside (2) structure decreased its IRI activity, indicating the importance of a delicate hydrophobic/hydrophilic balance within these compounds. The evaluation of various cation-phosphonate pairs was studied and revealed the IRI activity of ammonium and its ability to modulate the IRI activity of its paired anion. A preliminary cytotoxicity study was also performed in a HepG2 cell line and phosphonate analogues were found to have relatively low cytotoxicity. As such, we present phosphonate small-molecule carbohydrates as a biocompatible novel class of IRIs with high solubilities and moderate-to-high IRI activities.
\end{abstract}

Keywords: ice recrystallization; cryopreservation; carbohydrate chemistry

\section{Introduction}

The need for greatly improved cryopreservation strategies for cells and tissues has increased dramatically during the past decade and this need has been driven by numerous advances in cellular and regenerative therapies [1-4]. Current cryopreservation strategies often employ a cryoprotective agent (CPA) such as dimethyl sulfoxide (DMSO) and glycerol [5-14]. These CPAs offer varying degrees of protection against the cellular injury associated with cryopreservation $[15,16]$. While there are many different mechanisms by which cellular injury occurs during freezing and thawing, the majority of cellular injury occurs because of ice recrystallization $[17,18]$. Unfortunately, most CPAs and cryopreservation protocols do not control the growth of ice and ice recrystallization thus, the development of novel reagents/strategies to control ice recrystallization are urgently required.

Over the past years, our laboratory has synthesized several small molecule carbohydratebased ice recrystallization inhibitors (IRIs, Figure 1) and demonstrated their ability to enhance post-thaw recoveries and/or facilitate increased functional capacity in the cryopreservation of red blood cells (RBCs) [19-21], hematopoietic stem cells (HSCs) [22,23], and human umbilical vein endothelial cells (HUVECs) [24]. In particular, we have discovered that supplementation of $N$-(2-fluorophenyl)-D-gluconamide (3) with 10\% DMSO and dextran dramatically improves the engraftment capability of HSC progenitors from human umbilical cord blood in an immune-compromised mouse model [23]. More recently, we have been actively engaged in the rational design of small molecule IRIs that have improved physical and chemical properties (solubilities, bioavailabilities, etc.). Specifically, we have 
investigated how a negatively charged phosphonate group affects IRI activity when incorporated into two common molecular scaffolds of well-established small molecule ice recrystallization inhibitors (Figure 2). Previous literature reports have elucidated the role phosphate counterions play in altering the IRI activity of antifreeze proteins (AFPs) [25]. Thus, we envisioned a new class of IRI with a polar C-linked phosphate moiety (phosphonate) that would exhibit increased solubility in aqueous media. The phosphonate functional group is well tolerated in biological systems as a phosphate analogue and can greatly increase aqueous solubility [26,27]. A variety of counterions were evaluated including sodium, ammonium, potassium, and calcium (Figure 2).
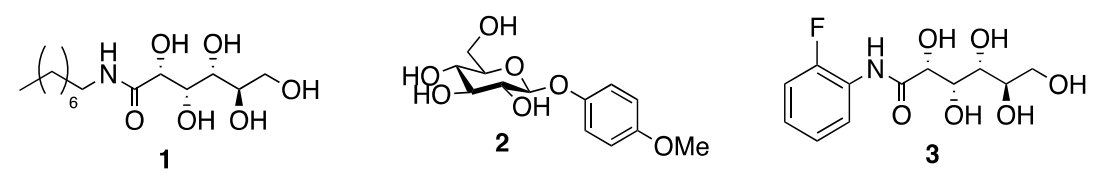

Figure 1. Structures of small molecule ice recrystallization inhibitors synthesized in the Ben laboratory.
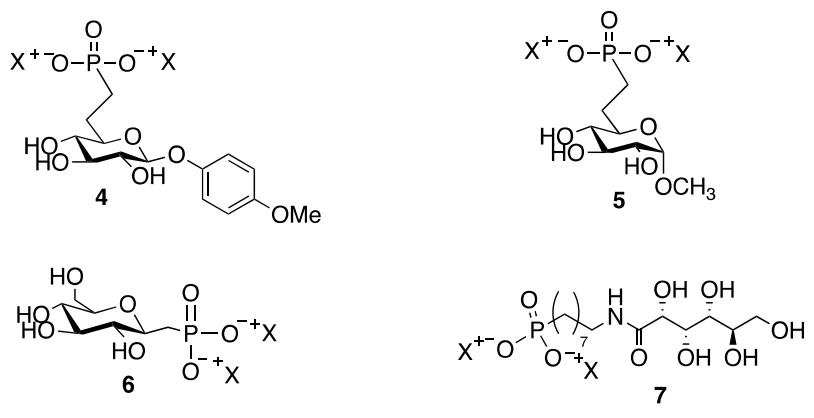

$\mathrm{X}=\mathrm{Na}^{+}, \mathrm{NH}_{4}^{+}, \mathrm{K}^{+}$, or $\mathrm{Ca}^{2+}$

Figure 2. Structures of phosphonate glycosides (4-6) and gluconamides (7).

Para-methoxyphenyl- $\beta$-D-glucopyranoside ( $\beta$-PMP-Glc) (2) exhibits potent IRI activity and has been used in the cryopreservation of red blood cells $[20,21,28]$. Prior structurefunction studies with this class of IRIs have indicated that the aryl ring and nature of the substituent is crucial for IRI activity [28] and that the C6-carbon of the pyranose was tolerant to various structural modifications. Therefore, the phosphonate moiety was introduced on the C6-carbon of the pyranose ring (4). In order to assess the functional importance of the aryl ring in phosphonate 4, the methoxy derivative 5 and C1-phosphonate 6 were also synthesized. Finally, the phosphonate derivative of gluconamide 1 was prepared and evaluated for IRI activity. The gluconamide class of IRIs are very effective inhibitors of ice recrystallization but have extremely low solubility in aqueous media.

\section{Materials and Methods}

\subsection{Ice Recrystallization Inhibition (IRI) Assay}

All compounds were measured for IRI activity using the modified splat cooling assay [29]. Samples were dissolved in phosphate-buffered saline (PBS) and a $10 \mu \mathrm{L}$ drop of the solution was dispensed from a height of 2 metres, onto a polished aluminum block cooled to $-78{ }^{\circ} \mathrm{C}$ with dry ice. The frozen wafer was carefully removed from the block, placed on a coverslip (Fisherbrand, 12-545-80, Canada) and transferred to a cryostage at $-6.4{ }^{\circ} \mathrm{C}$ connected to a cooling bath (Digital One RTE7 from Thermo Scientific NESLAB, US) and a Peltier unit (Series 800 temperature controller from Alpha Omega Instruments, US). The wafer was allowed to anneal at this temperature for $5 \mathrm{~min}$ and then photographed between crossed polarizing filters using a digital OEM Microscope Camera (Nikon) fitted to the microscope (20X objective). Images were viewed and captured using NIS Elements D software (version 5.30.01, Nikon Instruments, US, 2021) with the exposure set to $8 \mathrm{~ms}$. The images were analyzed using ImageJ software (Image Processing and Analysis in Java, 
version 1.51s, US, 2015), by circling each ice crystal with well-defined boundaries using a polygon function to generate the grain areas. The ice crystals are placed into "bins" according to their area where the smallest ice grain (size corresponding to the size of ice grain at $t$ $=0 \mathrm{~min}$ ) is considered "bin 1 " with increasing increments of $0.001 \mathrm{~mm}^{2}$. The proportion of ice crystals in each bin is used to determine the initial rate of ice recrystallization and is normalized against the PBS control $\left(v_{\text {norm }}\right)$ [30]. Different concentrations of each analyte are assessed and fitted to a sigmoidal curve using a four-parameter non-linear regression to generate a dose-response curve from which an $\mathrm{IC}_{50}$ value (the concentration that reduces the rate of ice recrystallization by $50 \%$ ) can be derived. This metric provides a quantitative measure of IRI activity.

\subsection{HepG2 Cell Culture}

HepG2 cells (human hepatocellular carcinoma cells, ATCC, HB-8065) were plated at a frequency of $1.5 \times 10^{6}$ cells, in a Corning ${ }^{\circledR}$ U-shaped T75 flask (Fisherbrand, 07-202-000, Canada), and cultured in Eagle's Minimum Essential Media (MEM, Sigma M4655, Canada) supplemented with 10\% Fetal Bovine Serum (FBS, heat inactivated US), 1\% penicillinstreptomycin (Fisherbrand, HyClone 100X solution, SV30010, Canada), 1\% non-essential amino acids (Sigma, M7145, Canada), and 0.1\% 1M sodium pyruvate. Cells were grown at a temperature of $37^{\circ} \mathrm{C}$ and $5 \% \mathrm{CO}_{2}$ and were washed every two days with Gibco ${ }^{\mathrm{TM}}$ DPBS (without Ca and Mg, Fisherbrand 14190136, Canada) and the culture media changed until $80 \%$ cell confluency was achieved. At $80 \%$ confluency, cells were detached with Accutase (Sigma, A6964, Canada) (incubated at $37^{\circ} \mathrm{C}$ for $15 \mathrm{~min}$ ) and a cell count was obtained by making a 1:4 dilution with Trypan Blue dye (Sigma, T8154, Canada) and using a hemocytometer.

\subsection{AlamarBlue ${ }^{T M}$ Assay for Cytotoxicity}

The cultured HepG2 cells were distributed in a 96-well plate at a concentration of 10,000 cells/well. The plate was incubated for $20-24 \mathrm{~h}$ at $37{ }^{\circ} \mathrm{C}$ and $5 \% \mathrm{CO}_{2}$, then centrifuged at $1000 \mathrm{rpm}$ for $5 \mathrm{~min}$. The supernatant in each well was removed via aspiration and either media (positive control), media supplemented with IRI, or media supplemented with $1 \%$ Triton $\mathrm{X}$ (negative control) was added to the appropriate wells. The plate was incubated for $20-24 \mathrm{~h}$ at $37{ }^{\circ} \mathrm{C}$ and $5 \% \mathrm{CO}_{2} .10 \mu \mathrm{L}$ of $12.5 \% w / v$ resazurin (Sigma, R7017, Canada) in Gibco ${ }^{\mathrm{TM}}$ DPBS (without Ca and Mg, Fisher 14190136, Canada) was added to each well and the plates were incubated for $4 \mathrm{~h}$ at $37{ }^{\circ} \mathrm{C}$ and $5 \% \mathrm{CO}_{2}$. The fluorescence (530 excitation/590 emission) was measured by a SpectraMax Absorbance microplate reader to obtain RFU readings, which were converted to cell viabilities via the following equation:

$$
\% \text { cell viability }=\left[\mathrm{RFU}_{(\mathrm{IRI})}-\mathrm{RFU}_{(\mathrm{neg})} / \mathrm{RFU}_{(\text {pos })}-\mathrm{RFU}_{(\mathrm{neg})}\right] \times 100 \%
$$

\section{Results}

Phosphonate compounds 4-7 were successfully synthesized according to the procedures outlined in the Supplementary Information.

\subsection{Solubility of Sodium Phosphonate Compounds}

Due to their polar nature, phosphonates readily form hydrogen bonds [26], and have been used to increase the solubility of organocatalysts [31,32] and drug-chelate supramolecular assemblies [33,34]. This property was consistent with our results as the solubilities of the sodium phosphonate analogues in phosphate-buffered saline (PBS) increased dramatically. Substituting a phosphonate moiety for a hydroxyl group in 2, resulted in a 3-fold increase in solubility for 4-Na and over 200-fold increase in solubility for 7-Na (the phosphonate analogue of $\mathbf{1}$ ) (Table 1). The other sodium phosphonate salts, 5-Na and 6-Na also exhibited high solubilities ( $>500 \mathrm{mM})$, confirming that incorporation of the 
sodium phosphonate functional group into the chemical structure of different saccharides is an effective strategy to increase solubility of the parent compound.

Table 1. The maximum solubility values in PBS of IRIs $1 \& 2$ and sodium phosphonate compounds (4-7).

\begin{tabular}{cc}
\hline Compound & Maximum Solubility in PBS (mM) \\
\hline $\mathbf{1}$ & 1 \\
$\mathbf{2}$ & 110 \\
$4-\mathrm{Na}$ & 300 \\
$5-\mathrm{Na}$ & $>500$ \\
$\mathbf{6}-\mathrm{Na}$ & $>500$ \\
$7-\mathrm{Na}$ & 250 \\
\hline
\end{tabular}

\subsection{IRI Analysis of Sodium Phosphonate Derivatives}

The splat cooling assay $[29,30]$ was used to assess the ability of IRI $\mathbf{1}$ and $\mathbf{2}$ and their phosphonate (4-7) derivatives to inhibit ice recrystallization. Amongst the phosphonate compounds, 7-Na displayed the highest degree of IRI activity $\left(\mathrm{IC}_{50}=21 \mathrm{mM}\right)$, followed by 5-Na $\left(\mathrm{IC}_{50}=28 \mathrm{mM}\right)$. Compounds 4-Na and 6-Na $\left(\mathrm{IC}_{50}=51\right.$ and $\left.51 \mathrm{mM}\right)$ displayed less IRI activity. $\mathrm{IC}_{50}$ values of $<30 \mathrm{mM}$, such as observed with $\mathbf{5 - N a}$ and $\mathbf{7 - N a}$, is an important requirement for use as a cryoprotectant in cells and tissues.

Relative to the parent compounds, the effect of the phosphonate moiety on IRI varied, but all phosphonate derivatives were IRI active. Installing the sodium phosphonate group at the C6-position of $\beta$-PMP-Glc (2) to generate derivative 4-Na resulted in a decrease of IRI activity, (a change in $\mathrm{IC}_{50}$ from $19 \mathrm{mM}$ to $51 \mathrm{mM}$ ). The fact that 4-Na exhibited an $\mathrm{IC}_{50}$ value of $51 \mathrm{mM}$ was not surprising as previous structure-function studies have indicated the C6-hydroxyl group in $\mathbf{2}$ is essential for IRI activity and that modification or removal abolishes its activity [28].

Similarly substituting the aryl group in phosphonate 4-Na with a methyl substituent (5-Na), resulted in an increase in IRI activity $\left(\mathrm{IC}_{50}=28 \mathrm{mM}\right)$. Compound 5-Na was one of the most effective inhibitors of ice recrystallization reported in this study. This was an unexpected result as prior structure-function studies of $\mathbf{2}$ indicated the aryl moiety was essential for IRI activity. In order to confirm the phosphonate in 5-Na was important for IRI activity, $\alpha$-methyl-D-glucoside ( $\alpha$-methGlc) was evaluated as a control. The $\mathrm{IC}_{50}$ value of $\alpha$-methGlc was $60 \mathrm{mM}$, approximately 3 times less active than $5-\mathrm{Na}$, demonstrating that the C6-phosphonate functionality was crucial to the IRI activity observed in 5-Na. However, changing the point of covalent attachment of the phosphonate group from the C6-position in 5-Na to the C1-position (6-Na) resulted in a decrease in IRI activity ( $\mathrm{IC}_{50}$ value for $28 \mathrm{mM}$ to $51 \mathrm{mM}$, respectively). This two-fold decrease in IRI activity confirmed that the position of functional groups around the saccharide ring is crucial to IRI activity, and that for the phosphonate glycoside class, C6-phosphonates are more active than C1-phosphonates.

$N$-alkyl gluconamides are another class of IRIs that have been discovered in our laboratory [34-36] However, this class of compounds has very limited solubility in aqueous media, thus increasing the solubility of these IRIs would enable their use as cryoprotective agents for the preservation of cells and tissues. Synthesizing 7-Na, by installing a sodium phosphonate at the terminal carbon of the octyl chain in $N$-octyl gluconamide (1), decreased its IRI activity by about 20-fold from an $\mathrm{IC}_{50}$ value of $0.09 \mathrm{mM}$ to $21 \mathrm{mM}$. Although 7-Na was the most IRI active out of all the phosphonate analogues prepared in this study and its $\mathrm{IC}_{50}$ value is below $30 \mathrm{mM}$, this was the least soluble of all phosphonate derivatives possessing the sodium counterion.

\subsection{IRI Activity of Phosphonate Compounds with Varying Counterions}

Prior work in our laboratory has demonstrated that counterions possessing a positive charge can modulate the IRI activity of surfactants that are IRI active [37]. Thus in the present study, we chose to prepare the ammonium, potassium, and calcium derivatives of phosphonate derivative 6 and compare the IRI activity to the sodium salt (6-Na, Figure 3). 
Ammonium counterions were attractive due to its ability to form multiple hydrogen bonds and calcium counterions were attractive as they are divalent and may facilitate the formation of aggregates in solution. Both of these factors have been hypothesized to contribute to IRI activity.
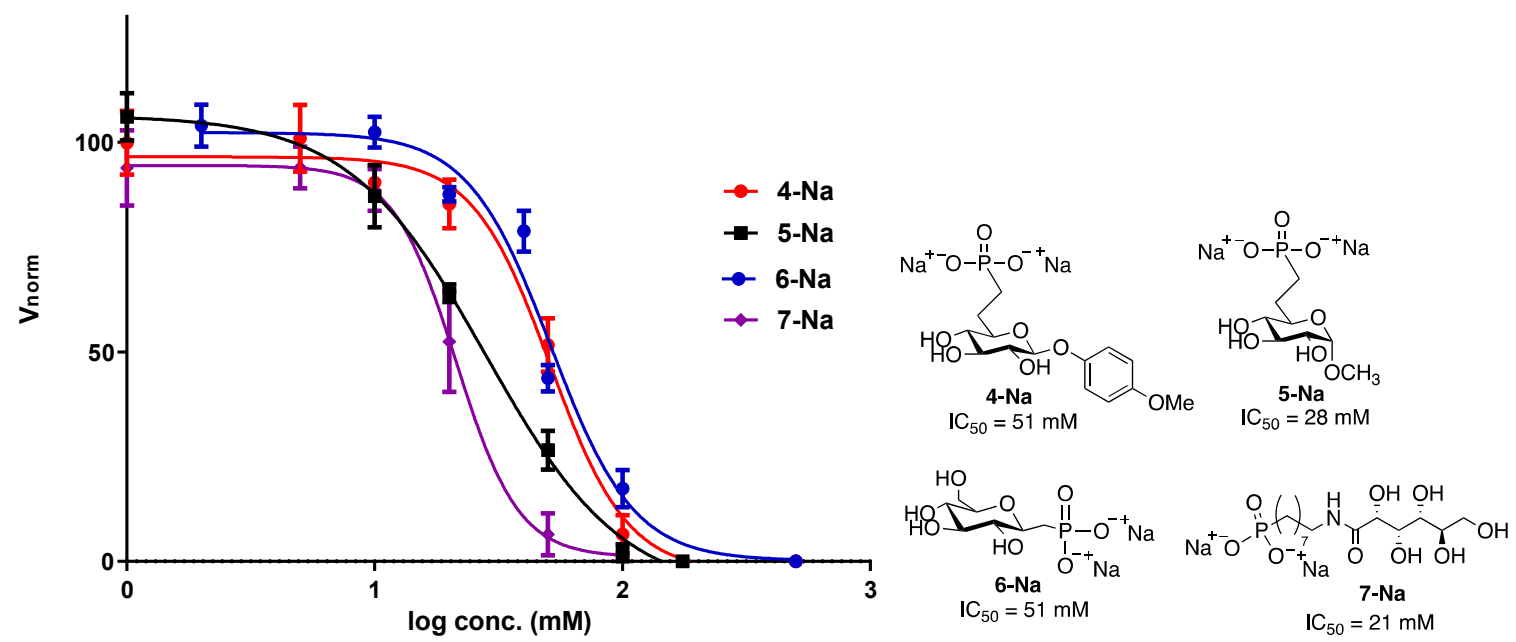

Figure 3. Structures and IRI activity of sodium phosphonate compounds 4-7. IRI activity is defined by dose response curves of the rate of ice recrystallization inhibition as a function of log concentration. Rates were measured in triplicate and were normalized against a phosphate-buffered saline (PBS) control. A non-linear regression curve was fitted to points to generate $\mathrm{IC}_{50}$ values. Error bars represent $\% \mathrm{SD}$ for $\mathrm{n}=3$ experiments.

The potassium and calcium phosphonate derivatives of $\mathbf{6}$ (6-K and 6-Ca) displayed IRI activity similar to that of 6-Na (Figure 4). However, the ammonium phosphonate derivative (6-NH $\mathrm{NH}_{4}$ ) was remarkably more IRI active than the corresponding sodium, potassium, and calcium derivatives (Figure 4). In fact, $6-\mathbf{N H}_{4}$ was the most active $\left(\mathrm{IC}_{50}=3 \mathrm{mM}\right.$ ) of all the sodium phosphonate compounds evaluated (4-Na, 5-Na, and 7-Na). These results suggested that the ammonium ion could possibly exhibit IRI activity on its own. To test this hypothesis, four inorganic ammonium salts $\left[\left(\mathrm{NH}_{4}\right)_{2} \mathrm{HPO}_{4},\left(\mathrm{NH}_{4}\right)_{2} \mathrm{CO}_{3}, \mathrm{NH}_{4} \mathrm{Cl}\right.$, and $\left(\mathrm{NH}_{4}\right)_{2} \mathrm{SO}_{4}$ ] were assessed for IRI activity. All the inorganic ammonium salts displayed similar activity to 6- $\mathrm{NH}_{4}$ (Table 2), indicating that the ammonium ion inhibits ice recrystallization. This was an unexpected result. In lieu of this, we assessed the IRI activity of sodium chloride, potassium chloride and calcium chloride (Table 2). No IRI activity was observed at the evaluated concentrations (see Supplementary Information, Figure S2), verifying that the activity observed with $6-\mathrm{Na}, 6-\mathrm{K}$ and $\mathbf{6 - C a}$ was a result of the pyranose phosphonate anion 6.

Since the pyranose phosphonate anion 5 is almost two times more active than $\mathbf{6}$, we sought to explore if converting 5 into an ammonium derivative $\left(5-\mathbf{N H}_{4}\right)$ would yield similar results or if it would be a more effective IRI than $\mathbf{6}-\mathrm{NH}_{4}$. Resultingly, phosphonate 5- $\mathrm{NH}_{4}$ exhibited an $\mathrm{IC}_{50}$ value of $2 \mathrm{mM}$, which was analogous to the other ammonium salts (Table 2). Thus, it appears that the activity of the paired anion has no influence on IRI activity in the presence of ammonium ions. Overall, this data shows that out of the surveyed counterions, ammonium is the only one that modulates the IRI activity of phosphonates $\mathbf{5}$ and $\mathbf{6}$. Sodium, potassium, and calcium counterions do not exhibit IRI activity and therefore do not modulate the IRI activity of paired phosphonate anions. 


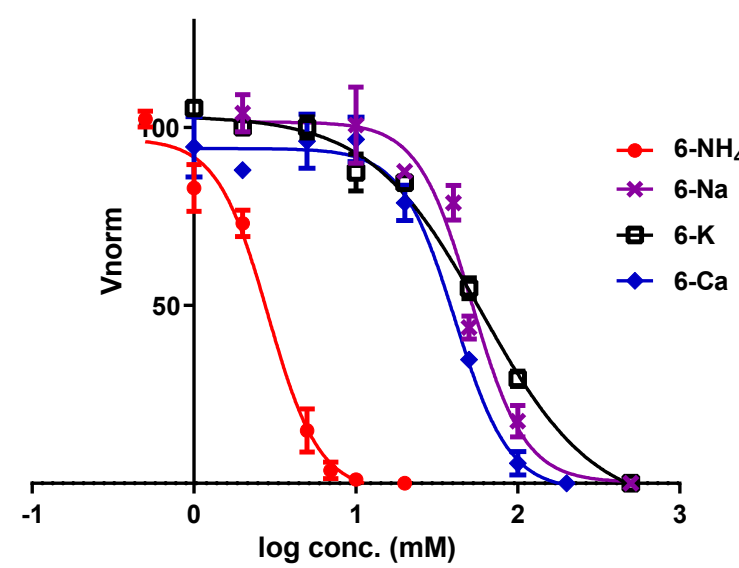

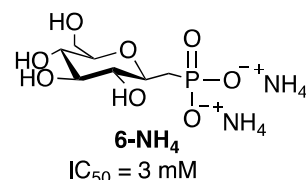
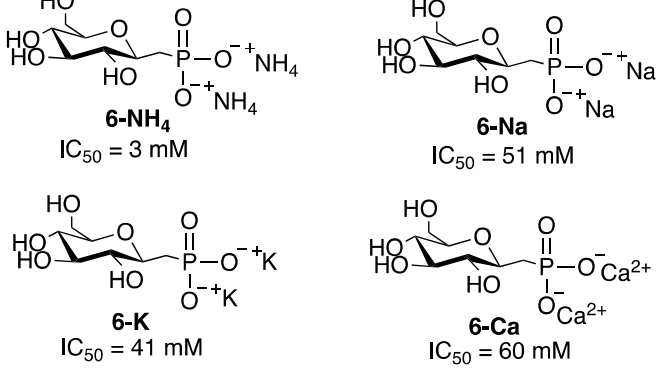

Figure 4. Structures and IRI activity of ammonium, sodium, potassium, and calcium phosphonate derivatives of 6. IRI activity is defined by dose response curves of the rate of ice recrystallization inhibition as a function of log concentration. Rates were measured in triplicate and were normalized against a phosphate-buffered saline (PBS) control. A non-linear regression curve was fitted to points to generate $\mathrm{IC}_{50}$ values. Error bars represent $\% \mathrm{SD}$ for $\mathrm{n}=3$ experiments.

Table 2. IRI activity of ammonium phosphonate derivatives of $\mathbf{5}$ and $\mathbf{6}$ and inorganic salts.

\begin{tabular}{cc}
\hline Compound & IC $_{\mathbf{5 0}}$ Values $^{\mathbf{1}}(\mathbf{m M})$ \\
\hline $\mathbf{6}-\mathrm{NH}_{\mathbf{4}}$ & 3 \\
$\left(\mathrm{NH}_{4}\right)_{2} \mathrm{HPO}_{4}$ & 2 \\
$\left(\mathrm{NH}_{4}\right)_{2} \mathrm{CO}_{3}$ & 2 \\
$\mathrm{NH}_{4} \mathrm{Cl}$ & 3 \\
$\left(\mathrm{NH}_{4}\right)_{2} \mathrm{SO}_{4}$ & 3 \\
$\mathrm{NaCl}^{2}$ & $\mathrm{~N} / \mathrm{A}^{2}$ \\
$\mathrm{KCl}$ & $\mathrm{N} / \mathrm{A}^{2}$ \\
$\mathrm{CaCl}_{2}$ & $\mathrm{~N} / \mathrm{A}^{2}$ \\
$5-\mathrm{NH}_{4}$ & 2 \\
\hline
\end{tabular}

${ }_{1}^{1} \mathrm{IC}_{50}$ values were generated from nonlinear regression curves fitted to points on a normalized rate vs. $\log$ concentration graph. ${ }^{2}$ A dose-response relationship was not observed for concentrations up to $100 \mathrm{mM}$.

\subsection{Toxicity of Phosphonates 5 and $\mathbf{6}$ in HepG2 Cells}

As a preliminary test, we evaluated the toxicity of ammonium and sodium phosphonates $\mathbf{5}$ and $\mathbf{6}$ in the presence of HepG2 cells to assess the biocompatibility of glycoside phosphonates. A resazurin-based assay [38,39] was utilized to assess the metabolic activity of mammalian cells when exposed to different concentrations of the phosphonates. The $\mathrm{LD}_{50}$ values of $\mathbf{5 - N a}, \mathbf{5}-\mathbf{N H}_{4}, \mathbf{6}-\mathbf{N a}$, and $\mathbf{6}-\mathbf{N H}_{\mathbf{4}}$ were calculated, from a fitted non-linear regression analysis, as $38 \mathrm{mM}, 16 \mathrm{mM}, 32 \mathrm{mM}$, and $24 \mathrm{mM}$, respectively.

The data presented in Figure 5 indicate that the ammonium phosphonate derivatives are more toxic than the sodium derivatives in HepG2 cells. It has been reported that HepG2 cells exposed to concentrations greater than $20 \mathrm{mM}$ of ammonium chloride result in excessive cell death [40]. Thus, the ammonium counterions may be increasing the cytotoxicity of 5-NH4 and $\mathbf{6}-\mathrm{NH}_{4}$. Another notable difference was the shape of the cytotoxicity curves of 5 and 6 (Figure 5). The Hill Slope of the curve in Figure 5A may indicate that HepG2 cells have a more rapid cytotoxic response to 5 versus 6 . However, at the IRI IC 50 values for $\mathbf{5}-\mathrm{NH}_{4}$ and $\mathbf{5 - N a}$ HepG2 cells were $100 \%$ viable. At concentrations equivalent to the $\mathrm{IC}_{50}$ value of $\mathbf{6}-\mathrm{NH}_{4}$, cells were $80 \%$ viable but at the IRI IC 50 value of $\mathbf{6}-\mathbf{N a}$, cells were only $15 \%$ viable. Our preliminary data is promising and shows that in both cases, phosphonate compounds are biocompatible and relatively low concentrations are not lethal; this is consistent with other organic phosphonates [41]. 
(A)

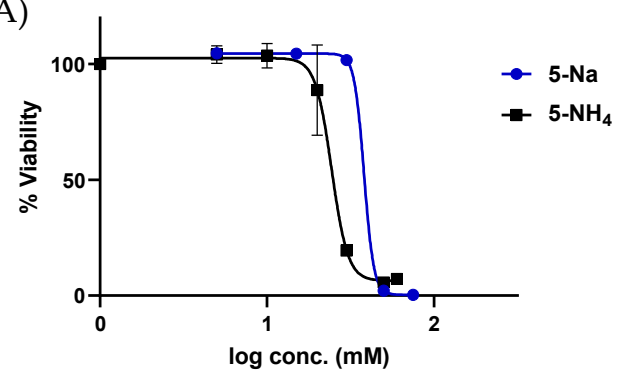

(B)

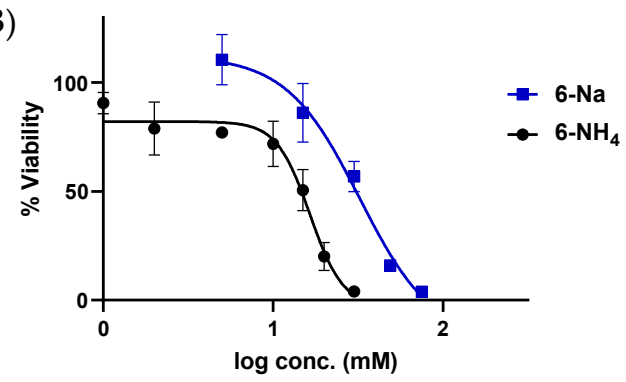

Figure 5. Plot of the \% viability in HepG2 cells as a function of log concentrations. (A) Dose response activity of 5-Na and 5- $\mathrm{NH}_{4}$ providing an $\mathrm{LD}_{50}$ of 38 and $16 \mathrm{mM}$. (B) Dose response activity of 6-Na and 6- $\mathbf{N H}_{4}$ providing an $\mathrm{LD}_{50}$ of 32 and $24 \mathrm{mM}$. A non-linear regression curve was fitted to points to generate $\mathrm{LD}_{50}$ values. Plates were run in duplicate with $n=7$ sample size. Error bars represent $\% \mathrm{SD}$.

\section{Discussion}

Several small-molecule IRIs have been synthesized in our laboratory to improve the cryopreservation of various cell types [19-24,28]. While these IRIs have demonstrated effectiveness as cryoprotectants, their low solubilities (attributed to the amphiphilic nature) are limiting for cellular applications. We have previously observed that amphiphilicity is an important factor that contributes to IRI activity, in which hydrophobicity (aryl ring or alkyl chain) and hydrophilicity (carbohydrate portion) must be delicately "balanced" [36,37,42]. The requirement of hydrophobic components often limits the solubilities of these compounds, which can be problematic during use at low cryopreservation temperatures. In order to maximize the ability of an IRI to control ice growth, we sought to significantly increase the solubility (>100 mM) of IRIs.

Our findings indicate that incorporation of a phosphonate moiety can dramatically improve the solubility of IRI active compounds. This was demonstrated with sodium phosphonates 5-Na and 7-Na. However, when compared to their parent compound, only sodium phosphonate $5-\mathrm{Na}$ exhibited a lower $\mathrm{IC}_{50}$ value thus emphasizing the importance of amphiphilicity in $\mathrm{O}$-aryl- $\beta$-D-glucosides and $\mathrm{N}$-alkyl-D-gluconamides. Installing a sodium phosphonate moiety to form 4-Na and 7-Na appeared to change the ideal balance of hydrophobicity and hydrophilicity resulting in a higher $\mathrm{IC}_{50}$ value. It is interesting that 5-Na was an effective IRI in the absence of a hydrophobic entity (aryl ring or alkyl chain). This suggests that an aryl or alkyl chain is not always required for IRI activity.

Our results also demonstrate that the IRI activity of an anionic IRI can be modulated by the presence of a cationic moiety such as ammonium, as the ammonium phosphonates along with the inorganic ammonium salts, displayed equal IRI activity to the parent compound. Prior work has revealed that a compound's ability to bind tightly to water molecules and form a non-exchangeable hydration layer contributes to IRI activity [43]. It has been reported that ammonium ions contain four hydrogen atoms that form strong hydrogen bonds to four water molecules resulting in a long-lived hydration cage [44-46]. Therefore, its ability to form strong hydrogen bonds may be the contributing factor for the low $\mathrm{IC}_{50}$ value observed. The ability of ammonium to increase the IRI activity of phosphonate compounds may be beneficial for cryopreservation purposes. Further in vitro cryopreservation studies are required to evaluate their efficacy as cryoprotectants.

The results from this study caution against making general predications for IRI activity when introducing a polar functional group in an IRI-active molecule. Although we have observed that it is possible for phosphonate compounds to have moderate-to-high IRI activity, the observations do not appear to apply to different classes of IRIs. Rather, each class of molecules must be assessed individually to determine their contributing factors to ice recrystallization inhibition. It is important to note that at his time it is not possible to infer how changes in the position of the phosphonate (i.e., $C 2, C 3, C 4$ in the pyranose ring) relative to the $C 1$ and $C 6$ positions may modulate IRI activity. The synthesis and IRI 
activity of analogues with a phosphonate moiety at other positions in the pyranose ring will be described in future studies.

More work must be done to fully understand the mechanism of how IRIs inhibit ice recrystallization as well as analyzing the different factors in each class of molecules that contribute to their mechanism of action. In addition, we aim to pursue in vitro cryopreservation studies with effective phosphonate IRIs in various cell types.

Supplementary Materials: The following are available online at https:/ /www.mdpi.com/article/10 .3390 /pr9101781/s1, Figure S1: IRI Activity of Inorganic Ammonium Salts and 6- $\mathbf{N H}_{\mathbf{4}}$, Figure S2: IRI Activity of (a) Sodium Chloride and 6-Na, (b) Potassium Chloride and 6-K and (c) Calcium Chloride.

Author Contributions: Conceptualization, A.A.A. and R.N.B.; methodology, A.A.A. and R.N.B.; formal analysis, A.A.A., K.N. and R.N.B.; writing—original draft preparation, A.A.A.; writingreview and editing, A.A.A. and R.N.B.; funding acquisition, R.N.B. All authors have read and agreed to the published version of the manuscript.

Funding: This research was funded by Natural Sciences and Engineering Research Council of Canada (NSERC RGPN-06298)), Canadian Institutes of Health Research (CIHR, 376748). A.A.A. acknowledges graduate support (Graduate Fellowship Program) from Canadian Blood Services (CBS).

Institutional Review Board Statement: Not applicable.

Informed Consent Statement: Not applicable.

Conflicts of Interest: The authors declare no conflict of interest.

\section{References}

1. Jang, T.H.; Park, S.C.; Yang, J.H.; Kim, J.Y.; Seok, J.H.; Park, U.S.; Choi, C.W.; Lee, S.R.; Han, J. Cryopreservation and Its Clinical Applications. Integr. Med. Res. 2017, 6, 12-18. [CrossRef]

2. Jahan, S.; Kaushal, R.; Pasha, R.; Pineault, N. Current and Future Perspectives for the Cryopreservation of Cord Blood Stem Cells. Transfus. Med. Rev. 2021, 35, 1-8. [CrossRef] [PubMed]

3. Meneghel, J.; Kilbride, P.; Morris, G.J. Cryopreservation as a Key Element in the Successful Delivery of Cell-Based TherapiesA Review. Front. Med. 2020, 7, 1-17. [CrossRef] [PubMed]

4. Giwa, S.; Lewis, J.K.; Alvarez, L.; Langer, R.; Roth, A.E.; Church, G.M.; Markmann, J.F.; Sachs, D.H.; Chandraker, A.; Wertheim, J.A.; et al. The Promise of Organ and Tissue Preservation to Transform Medicine. Nat. Biotechnol. 2017, 35, 530-542. [CrossRef] [PubMed]

5. Lahmann, J.M.; Sanchez, C.C.; Benson, J.D.; Acker, J.P.; Higgins, A.Z. Implications of Variability in Cell Membrane Permeability for Design of Methods to Remove Glycerol from Frozen-Thawed Erythrocytes. Cryobiology 2020, 92, 168-179. [CrossRef]

6. Awan, M.; Buriak, I.; Fleck, R.; Fuller, B.; Goltsev, A.; Kerby, J.; Lowdell, M.; Mericka, P.; Petrenko, A.; Petrenko, Y.; et al. Dimethyl Sulfoxide: A Central Player since the Dawn of Cryobiology, Is Efficacy Balanced by Toxicity? Regen. Med. 2020, 15, $1463-1491$. [CrossRef]

7. Baboo, J.; Kilbride, P.; Delahaye, M.; Milne, S.; Fonseca, F.; Blanco, M.; Meneghel, J.; Nancekievill, A.; Gaddum, N.; Morris, G.J. The Impact of Varying Cooling and Thawing Rates on the Quality of Cryopreserved Human Peripheral Blood T Cells. Sci. Rep. 2019, 9, 1-13. [CrossRef]

8. Rall, W.F.; Mazur, P.; Souzu, H. Physical-Chemical Basis of the Protection of Slowly Frozen Human Erythrocytes by Glycerol. Biophys. J. 1978, 23, 101-120. [CrossRef]

9. Honadel, T.E.; Killian, G.J. Cryopreservation of Murine Embryos with Trehalose and Glycerol. Cryobiology 1988, 25, 331-337. [CrossRef]

10. Krijnen, H.W.; de Wit, J.J.; Kuivenhoven, A.C.; Loos, J.A.; Prins, H. Glycerol Treated Human Red Cells Frozen with Liquid Nitrogen. Vox Sang 1964, 9, 559-572. [CrossRef]

11. Meira, C.; Alvarenga, M.A.; Papa, F.O.; Oba, E.; Alvarenga, F.C.L. Cryopreservation of Equine Embryos Using Glycerol and 1,2-Propanediol as Cryoprotectants. Equine Vet. J. 2010, 25, 64-66. [CrossRef]

12. Lovelock, J.E. Het Mechanism of the Protective Action of Glycerol against Haemolysis by Freezing and Thawing. Biochim. Biophys. Acta 1953, 11, 28-36. [CrossRef]

13. Meryman, H.T.; Hornblower, M. A Method for Freezing and Washing Red Blood Cells Using a High Glycerol Concentration. Transfusion 1972, 12, 145-156. [CrossRef]

14. Fahy, G.M. Analysis of "Solution Effects" Injury: Rabbit Renal Cortex Frozen in the Presence of Dimethyl Sulfoxide. Cryobiology 1980, 17, 371-388. [CrossRef]

15. Lovelock, J.E. The Protective Action of Neutral Solutes against Haemolysis by Freezing and Thawing. Biochem. J. 1954, 56, 265-270. [CrossRef] 
16. Lovelock, J.E.; Bishop, M.W.H. Prevention of Freezing Damage to Living Cells by Dimethyl Sulphoxide. Nature 1959, 183, 1394-1395. [CrossRef] [PubMed]

17. Mazur, P. Cryobiology: The Freezing of Biological Systems. Science 1970, 168, 939-949. [CrossRef] [PubMed]

18. Mazur, P. Freezing of Cells: Mechanisms and Implications. Am. J. Physiol. 1984, 247, C125-C142. [CrossRef]

19. Poisson, J.S.; Briard, J.G.; Turner, T.R.; Acker, J.P.; Ben, R.N. Hydroxyethyl Starch Supplemented with Ice Recrystallization Inhibitors Greatly Improves Cryopreservation of Human Red Blood Cells. Bioprocess. J. 2017, 15, 16-21. [CrossRef]

20. Capicciotti, C.J.; Kurach, J.D.; Turner, T.R.; Mancini, R.S.; Acker, J.P.; Ben, R.N. Small Molecule Ice Recrystallization Inhibitors Enable Freezing of Human Red Blood Cells with Reduced Glycerol Concentrations. Nat. Sci. Rep. 2015, 5, 9692. [CrossRef]

21. Briard, J.G.; Poisson, J.S.; Turner, T.R.; Capiccioti, C.J.; Acker, J.P.; Ben, R.N. Small Molecule Ice Recrystallization Inhibitors Mitigate Red Blood Cell Lysis during Freezing, Transient Warming and Thawing. Sci. Rep. 2016, 6, 23619. [CrossRef] [PubMed]

22. Briard, J.G.; Jahan, S.; Chandran, P.; Allan, D.; Pineault, N.; Ben, R.N. Small-Molecule Ice Recrystallization Inhibitors Improve the Post-Thaw Function of Hematopoietic Stem and Progenitor Cells. ACS Omega 2016, 1, 1010-1018. [CrossRef]

23. Jahan, S.; Adam, M.K.; Manesia, J.K.; Doxtator, E.; Ben, R.N.; Pineault, N. Inhibition of Ice Recrystallization during Cryopreservation of Cord Blood Grafts Improves Platelet Engraftment. Transfusion 2020, 60, 769-778. [CrossRef]

24. Poisson, J.S.; Acker, J.P.; Briard, J.G.; Meyer, J.E.; Ben, R.N. Modulating Intracellular Ice Growth with Cell-Permeating SmallMolecule Ice Recrystallization Inhibitors. Langmuir 2019, 35, 7452-7458. [CrossRef]

25. Suris-Valls, R.; Voets, I.K. The Impact of Salts on the Ice Recrystallization Inhibition Activity of Antifreeze (Glyco)Proteins. Biomolecules 2019, 9, 347. [CrossRef] [PubMed]

26. Sevrain, C.M.; Berchel, M.; Couthon, H.; Jaffrès, P.-A. Phosphonic Acid: Preparation and Applications. Beilstein J. Org. Chem. 2017, 13, 2186-2213. [CrossRef] [PubMed]

27. Déjugnat, C.; Etemad-Moghadam, G.; Rico-Lattes, I. Asymmetric Synthesis of ( $\alpha$-Amino) Phosphonic Acid Amphiphiles Using Chiral P-H Spirophosphoranes. Chem. Commun. 2003, 1858-1859. [CrossRef]

28. Capicciotti, C.J.; Mancini, R.S.; Turner, T.R.; Koyama, T.; Alteen, M.G.; Doshi, M.; Inada, T.; Acker, J.P.; Ben, R.N. O-Aryl-Glycoside Ice Recrystallization Inhibitors as Novel Cryoprotectants: A Structure-Function Study. ACS Omega 2016, 1, 656-662. [CrossRef]

29. Knight, C.A.; Hallett, J.; Devries, A.L. Solute Effects on Ice Recrystallization: An Assessment Technique. Cryobiology 1988, 25, 55-60. [CrossRef]

30. Abraham, S.; Keillor, K.; Capiccioti, C.J.; Perley-Robertson, E.; Keillor, J.W.; Ben, R.N. Quantitative Analysis of the Efficacy and Potency of Novel Small Molecule Ice Recrystallization Inhibitors. Cryst. Growth Des. 2015, 15, 5034-5039. [CrossRef]

31. Glöckler, J.; Klützke, S.; Meyer-Zaika, W.; Reller, A.; García-García, F.J.; Strehblow, H.H.; Keller, P.; Rentschler, E.; Kláui, W. With Phosphinophosphonic Acids to Nanostructured, Water-Soluble, and Catalytically Active Rhodium Clusters. Angez. Chem. Int. Ed. 2007, 46, 1164-1167. [CrossRef] [PubMed]

32. Cortes-Clerget, M.; Gager, O.; Monteil, M.; Pirat, J.L.; Migianu-Griffoni, E.; Deschamp, J.; Lecouvey, M. Novel Easily Recyclable Bifunctional Phosphonic Acid Carrying Tripeptides for the Stereoselective Michael Addition of Aldehydes with Nitroalkenes. Adv. Synth. Catal. 2016, 358, 34-40. [CrossRef]

33. Bayrakc, M.; Ertul, S..; Yilmaz, M. Transportation of Poorly Soluble Drug Molecules from the Organic Phase to the Aqueous Phase by Using Phosphorylated Calixarenes. J. Chem. Eng. Data 2011, 56, 4473-4479. [CrossRef]

34. Martin, A.D.; Boulos, R.A.; Stubbs, K.A.; Raston, C.L. Phosphonated Calix [4] Arene-Based Amphiphiles as Scaffolds for Fluorescent Nano-Fibres. Chem. Comm. 2011, 47, 7329-7331. [CrossRef]

35. Capicciotti, C.J.; Leclere, M.; Perras, F.A.; Bryce, D.L.; Paulin, H.; Harden, J.; Liu, Y.; Ben, R.N. Potent Inhibition of Ice Recrystallization by Low Molecular Weight Carbohydrate-Based Surfactants and Hydrogelators. Chem. Sci. 2012, 3, 1408-1419. [CrossRef]

36. Ampaw, A.; Charlton, T.A.; Briard, J.G.; Ben, R.N. Designing the next Generation of Cryoprotectants-from Proteins to Small Molecules. Peptide Sci. 2019, 111, 1-12. [CrossRef]

37. Balcerzak, A.K.; Febbraro, M.; Ben, R.N. The Importance of Hydrophobic Moieties in Ice Recrystallization Inhibitors. RSC Adv. 2013, 3, 3232-3236. [CrossRef]

38. Larson, E.M.; Doughman, D.J.; Gregerson, D.S.; Obritsch, W.F. A New, Simple, Nonradioactive, Nontoxic in Vitro Assay to Monitor Corneal Endothelial Cell Viability. Invest. Ophthalmol. Vis. Sci. 1997, 38, 1929-1933.

39. O'Brien, J.; Wilson, I.; Orton, T.; Pognan, F. Investigation of the Alamar Blue (Resazurin) Fluorescent Dye for the Assessment of Mammalian Cell Cytotoxicity. Eur. J. Biochem. 2000, 267, 5421-5426. [CrossRef]

40. Li, J.; Yu, Z.; Wang, Q.; Li, D.; Jia, B.; Zhou, Y.; Ye, Y.; Shen, S.; Wang, Y.; Li, S.; et al. Hyperammonia Induces Specific Liver Injury through an Intrinsic $\mathrm{Ca}^{2+}$-Independent Apoptosis Pathway. BMC Gastroenterol. 2014, 14, 1-10. [CrossRef] [PubMed]

41. Hostetler, K.Y. Alkoxyalkyl Prodrugs of Acyclic Nucleoside Phosphonates Enhance Oral Antiviral Activity and Reduce Toxicity: Current State of the Art. Antivir. Res. 2009, 82, A84-A98. [CrossRef]

42. Trant, J.F.; Biggs, R.A.; Capicciotti, C.J.; Ben, R.N. Developing Highly Active Small Molecule Ice Recrystallization Inhibitors Based upon C-Linked Antifreeze Glycoprotein Analogues. RSC Adv. 2013, 3, 26005-26009. [CrossRef]

43. Tam, R.Y.; Ferreira, S.S.; Czechura, P.; Chaytor, J.L.; Ben, R.N. Hydration Indexes-A Better Parameter for Explaining Small Molecule Hydration in Inhibition of Ice Recrystallization. J. Am. Chem. Soc. 2008, 130, 17494-17501. [CrossRef] [PubMed]

44. Noto, R.; Martorana, V.; Migliore, M.; Fornili, S.L. Hydration of the Ammonium Ion: Monte Carlo Simulation. Z. Nat. A 1991, 46, 107-110. [CrossRef] 
45. Brugé, F.; Bernasconi, M.; Parrinello, M. Ab Initio Simulation of Rotational Dynamics of Solvated Ammonium Ion in Water. J. Am. Chem. Soc. 1999, 121, 10883-10888. [CrossRef]

46. Brugé, F.; Bernasconi, M.; Parrinello, M. Density-Functional Study of Hydration of Ammonium in Water Clusters. J. Chem. Phys. 1999, 110, 4734. [CrossRef] 